\title{
Upper Midwest farmer perceptions: Too much uncertainty about impacts of climate change to justify changing current agricultural practices
}

\author{
L.W. Morton, G. Roesch-McNally, and A.K. Wilke
}

\begin{abstract}
To be uncertain is to be unsure or have doubt. Results from a random sample survey show the majority $(89.5 \%)$ of farmers in the Upper Midwest perceived there was too much uncertainty about the impacts of climate to justify changing their agricultural practices and strategies, despite scientific evidence regarding the causes and potential consequences of climate change. This study uses random sample survey data $(n=4,778)$ and in-depth interviews $(n=159)$ of Upper Midwest farmers to better understand factors that underlie their uncertainty and reluctance to take adaptive action. Results reveal that farmers' uncertainty about projected climate change impacts on their production systems is influenced by their beliefs about climate change, experiences with drought, concern about heat stress on crops, and agricultural information networks. Findings suggest a combination of insufficient information and normative influences on climate beliefs are influencing farmer uncertainty. In cases where uncertainty is caused by insufficient information, improved farmer access to and use of historical crop and local climate records, as well as decision support tools that simulate different climate scenarios and their impacts on production, could improve estimates of future risks. However, more information may be insufficient to address claims of uncertainty when differing political and cultural norms contest the parameters of climate change. This suggests that scientific knowledge must be linked to social values and beliefs and trusted agricultural networks for widespread adaptive management to a changing climate to occur.
\end{abstract}

Key words: adaptive management-beliefs_climate change-information sourcesuncertainty-Upper Midwest farmers

Scientific messages about climate change document high levels of certainty about current and projected patterns of more variable and extreme weather in the United States, including increased average precipitation, increased heavy downpours, on-average more frequent heat waves, more regional flooding and droughts, and a longer frost-free crop season (Walsh et al. 2014). All of these trends have the potential to affect agricultural crop yields and soil and water resources. There is growing pressure on farmers to proactively make climate adaptation-related decisions to reduce vulnerability to their production systems, to better manage and avoid degradation of soil and water resources, and to assure ecosystem resilience under increasingly variable climate back in time millions of years before humans. Thus, it is not surprising that climate change is difficult to predict or interpret, especially at human time scales and at very local levels (Gleick 2012; Weber and Stern 2011; Dahlstrom 2014). Scientists often quantify uncertainty using probabilities and ranges based on analyses that measure the level of certainty associated with climate change projections (Morss et al. 2005; Kettle and Dow 2016). This helps them to find trends from historical climate records and model projections about future climate conditions. Climate science is evolving, and there continues to be much that is not known about the earth-atmospheric interactions. While there is scientific consensus of a global warming trend and increased variability in weather, uncertainty remains about potential impacts of temperature and precipitation patterns to cropping systems at regional and localized scales (Arritt 2016; Hatfield et al. 2011).

There are a number of reasons why farmers may claim uncertainty and unwillingness to make adjustments in how they manage their systems. Farmers may misjudge the risk of climate as a hazard (Slovic 2009). They may interpret scientific uncertainty and incomplete scientific information as a lack of scientific consensus on the broad dynamics of climate change (Sarewitz 2004). This could lead to assumptions of insufficient information and a decision to not act until better information is available (Simon 1959; Ingham et al.2007; Slovic 2009).Additionally, the political and social meanings associated with climate change may be contrary to their values and beliefs, thus making climate science a contested field, causing distrust and unwillingness for action (Sarewitz 2004). The facts about climate change may not be relevant or congruent with their own experiences or historical narratives about local weather patterns, and so they have not yet framed changing conditions as a "problem" they need to solve (Sarewitz 2004; Morton et al. 2015; Wilke and Morton 2016).

Lois Wright Morton (corresponding author) is a professor in the Department of Sociology at lowa State University in Ames, lowa. Gabrielle Roesch-McNally is a postdoctoral fellow with the USDA Northwest Regional Climate Hub in Corvallis, Oregon. Adam K. Wilke is a research social scientist with the US Geological Survey in Fort Collins, Colorado (work represented here was conducted while affiliated with lowa State University). 


\section{Figure 1}

Upper Midwest corn-soybean farmers' self-report that they agree or strongly agree "there is too much uncertainty about the impacts of climate change to justify changing my agricultural practices and strategies" by hydrologic unit code (HUC) 6 watersheds $(n=3,267)$.

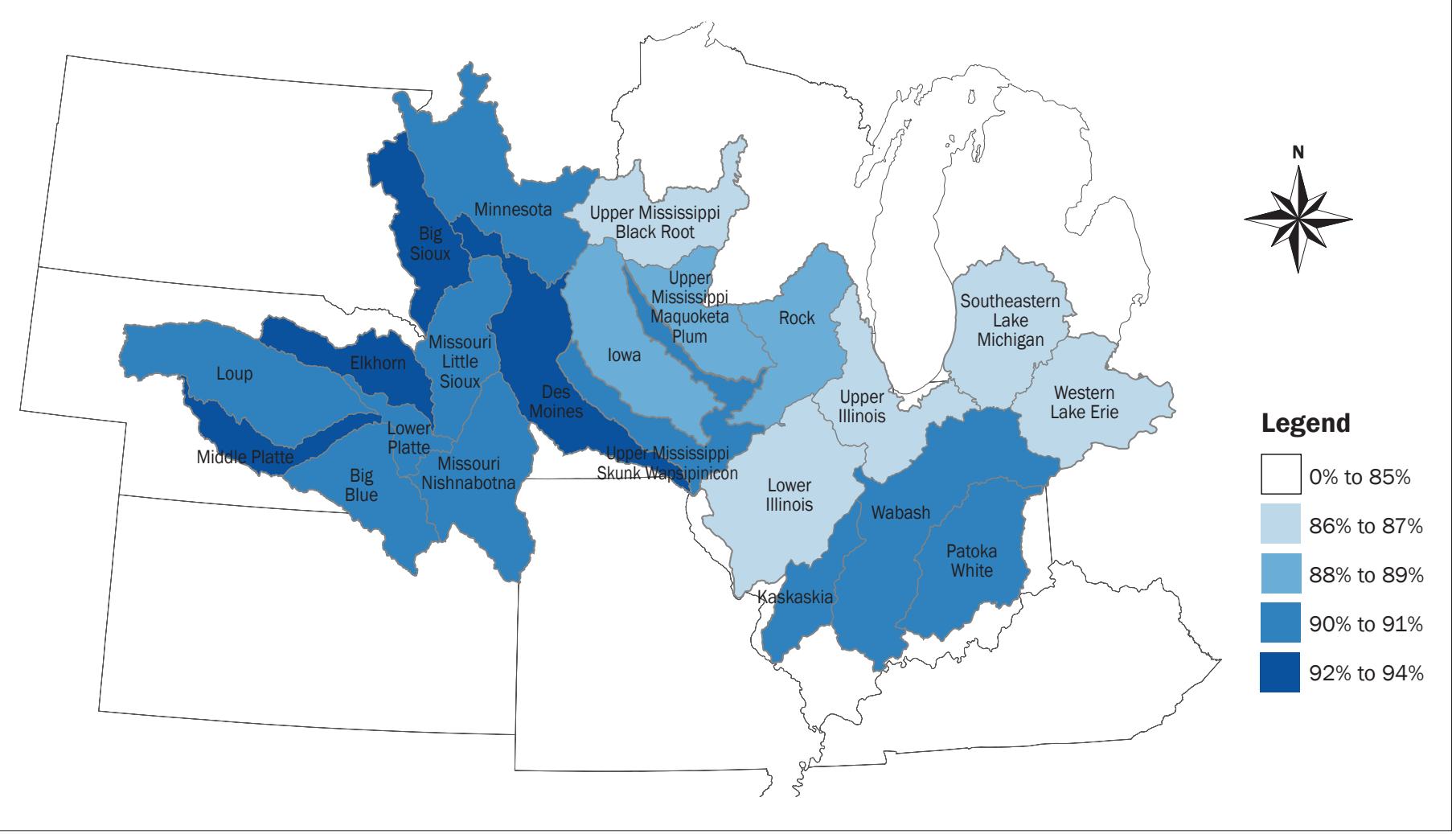

Responding to climate change entails recognizing and adjusting to experienced or anticipated risks that arise from short-term weather events and longer-term climate trends (Adger et al. 2013). Recent research has found that farmers have differential adaptive management responses based on locale-specific climate, weather, and soils, as well as personal experiences (Morton et al. 2015). For example, Morton et al. (2015) report that experience with saturated soils was significantly associated with increased drainage use, less use of no-till and cover crops, and increased likelihood of planting on highly erodible lands.

While farmers have some routine level of experience in dealing with uncertain seasonal weather variability (Walthall et al. 2012), they are experiencing increases in the range of variability (Crane et al. 2011). This increased variability may be a source of uncertainty, as the local impacts of weather could seem to be sufficiently unpredictable to warrant a "wait-and-see" attitude rather than a decisive response. Adger et al. (2009) conclude, "... given that climate and impact projections at the regional and local level are subject to deep uncertainties, one would expect this lack of certainty - this lack of accurate and precise foreknowledge - to act as an important limit to adaptation efforts." In this context, "too much" uncertainty may imply farmers are unsure of the best path forward; thus it appears that continuing with their current management approach seems the most reasonable decision until more evidence or information points towards a different decision (Nowak 1992).

Although beliefs and perceptions of risk associated with climate change continue to be unsettled (Arbuckle et al. 2015; Adger et al. 2013), a connection between climate change beliefs and willingness to adapt is emerging. A number of scholars have linked adaptation responses to beliefs and the level of certainty associated with climate change and consequences to human and natural systems (Adger et al. 2009, 2013; Arbuckle et al. 2013a, 2013c, 2014; Prokopy et al. 2013). Arbuckle et al. (2013c) report that farmers who attribute climate change to natural causes or who don't think there is enough evidence that climate change is occurring are likely to be less supportive of adaptive and mitigative action. If uncertainty is a barrier to adaptation, a greater understanding about the factors that influence farmer perceptions that too much uncertainty exists to take action is needed.

In this paper, underlying factors that affect corn (Zea mays)-soybean (Glycine max L.) farmers' judgments of uncertainty associated with climate change are explored. Building on prior literatures, a model consisting of four concepts-(1) beliefs about climate change, (2) firsthand experiences with excess water and drought, (3) concerns about water and heat stress risks to production, and (4) agricultural networks - is constructed to test their influence on perceptions of too much uncertainty about the impacts of climate change to justify changing agricultural practices and strategies.

The following section outlines key concepts and definitions of uncertainty applied to climate change and adaptation in agriculture. Then hypotheses are constructed to examine factors that influence farmers' claims of too much uncertainty about climate change to justify making changes in their current production system. The study utilizes a 2012 random sample survey of 4,778 Upper Midwest farmers and an analysis of interviews with 159 farmer cooperators to test 
and elaborate the findings of the proposed hypotheses. Qualitative in-depth farmer interviews are integrated with the results of a binary logistic regression model to develop a deeper understanding of farmer assessments of uncertainty associated with weather, climate, and their systems of production. Following a discussion of the findings and implications, concluding thoughts and recommendations are presented.

Uncertainty. To be uncertain is to be unsure or have doubt about a situation, a person, or a decision. There are a variety of social, economic, relational, and biophysical factors that can influence uncertainty. Some scholars link imperfect information to uncertainty; that is, there is not enough information to be sure at some level (Simon 1959; Ingham et al. 2007; Slovic 2009). Bounded rationality theory (Simon 1959) posits that most people are constrained by limitations of perception and education and are likely to use trial and error rather than conduct formal analyses to better understand the world. Informal and experiential cues are considered adequate and satisfy rather than optimize goals. People and the institutions they are associated with have different levels of tolerance for uncertainty and different strategies for reducing it when there seems to be a benefit in doing so. In general, people typically look for certainty and avoid uncertainty when deciding how to act in their everyday lives (Slovic 2009; Rabinovich and Morton 2012).

A claim of scientific uncertainty is often interpreted by the nonscientific public as a sign of incompetence or poor understanding about a topic (Frewer et al. 2003) rather than an admission of incomplete information. There is evidence that people tend to discount information labeled "uncertain" in the process of decision making, and are less likely to use information that conveys uncertainty (Rabinovich and Morton 2012). This misinterpretation of uncertainty projections in climate science can influence farmers' beliefs about climate change and reduce acceptance and willingness to act on projected climate change conditions into the future. Claims and counterclaims produce competing interpretations of science and what it means, and this allows people with different beliefs and values to find the scientific facts that are congruent with their values and support their action (or inaction).

Some theories frame uncertainty as a continuum from deterministic knowledge to total ignorance (Kettle and Dow 2016). A corollary to this in classical models is that perfect knowledge resolves uncertainty and the goal of scientific inquiry is to produce more knowledge so as to more closely approach perfect knowledge (Ingham et al. 2007). It follows from this line of reasoning that decision makers know that, over time, they are likely to receive more information about climate change as the scientific knowledge builds and this improved knowledge will reduce uncertainty associated with decisions (Ingham et al.2007). The expectation of new knowledge in the future may be a reason for delaying current actions. The decision maker could decide it pays to keep one's options open (e.g., "wait-and-see") and to adapt only when better information is available. Under this scenario, a farmer has to decide the benefits of (1) adapting their production system now, based on currently available scientific findings about climate, or (2) waiting until future information reduces the uncertainty associated with current science so as to better choose the adaptation investment best suited to their operation.

Does more knowledge inevitability reduce uncertainty and how people approach scientific research and its applications? Rabinovich and Morton (2012) propose that beliefs about the scientific process and levels of uncertainty communicated about scientific phenomenon can affect willingness to act on messages that call for adapting to climate change. They contrast two models of the nature of science that underlie the meanings assigned to uncertainty. The classical model of science views objective science as providing a set of empirically tested observations or "truths" about a particular phenomenon. This leads to a belief that the goal of science is to uncover objective truth about the world and provide solid proof of this knowledge. Thus, as science creates more information, uncertainty decreases until it is finally eliminated, leaving only certainty.

Another model views science as unanswered questions, whereby the process of seeking answers leads to more questions rather than definitive truth. This view considers science as a series of paradigms (Kuhn 1962) in which scientific theories and findings are debated and iteratively revised as new data are gathered, analyzed, and lead to new discoveries that replace prior scientific knowledge. Inherent in this model is the critical role of uncertainty whereby no one truth solves the problem of uncertainty. New uncertainties arise even as more knowledge is gained. In this process, science is spurred on to better understand greater complexity and build new knowledge. Rabinovich and Morton (2012) find that those who seek objective truth are more likely to report higher level of intolerance to uncertainty than those who share Kuhn's conceptualization of uncertainty as part of the knowledge construction process. Applied to farmers, those who are expecting that scientific projections about precipitation, temperature, and other measures of weather and climate trends will be spatially and temporally 100\% or even 95\% accurate will not just be disappointed, but will also be more likely to have greater uncertainty about whether and how they should adapt.

Literatures that find the risks of natural hazards are often misjudged by nonscientific publics suggest that differences in assessments of uncertainty between scientists and the lay public - such as farmers-lie in a lack of understanding and interpretation of the probabilities of potential risk and limited skills in applying them in practical ways (Slovic 2009). This view, that more information and greater understanding of the science would reduce farmer uncertainty, is challenged by recent literature on postnormal science (Sarewitz 2004; Funtowicz and Ravetz 1993; Batie 2008). "Normal science" is defined by the assumption that if we get the science right, we can solve social problems like climate change (Batie 2008; Wilke and Morton 2015a; Pielke 2007). This linear framing assumes the cause of uncertainty and inaction as one of insufficient information. Postnormal science proposes that where system uncertainties or decision stakes are high, science becomes issue driven by a competing diversity of ethics and values (Funtowicz and Ravetz 1993). Sarewitz (2004) elaborates on this view claiming that differences in values and what are considered legitimate facts about nature, rather than lack of scientific understanding, is a root cause of uncertainty and inaction. Further, he observes that science is coproduced by scientists and society with different stakeholders possessing different bodies of contextually validated knowledge (Sarewitz 2004). This framing suggests uncertainty about climate change is derived from competing beliefs and understanding about climate, which are amplified by political and cultural contexts. 
People who make decisions under uncertainty often seek information from trusted institutions to make sense of and reduce uncertainty (Arbuckle et al. 2015; Kahan et al. 2011; Weber and Stern 2011; Dietz et al. 2007). If farmers believe their social networks to be trustworthy, then they are more likely to trust the knowledge that comes from that social network (Carolan 2006). This suggests that trust in government, climate scientists, Extension, and/or crop advisors may reduce the complexity of risk management associated with climate impacts and uncertainty (Laurian 2009; Haigh et al. 2015). Some research has found that farmers who trust private sector agricultural advisors may be less likely to believe in climate change and therefore may be more uncertain when it comes to responding to climate risks than farmers who trust more public and conservation-oriented information sources (Arbuckle et al. 2013b). Recent work by Arbuckle et al. (2015) reports that farmers who trust agriculturally oriented institutions, both public or private, are less likely to believe in climate change and deny a connection between climate change and human activity compared to environmentally oriented institutions. Prokopy et al. (2015) similarly present evidence that private agricultural advisors tend to have more similar beliefs about climate change as farmers when compared to other types of agricultural advisors. As a result, it is not entirely clear as to what effects public and private agricultural interests have on reducing or increasing uncertainty.

Funtowicz and Ravetz (1993) report that situations characterized by high stakes and large uncertainties often lead to the interpretation of facts in terms of values and beliefs. As a result, scientific facts and individual values can become so intertwined that they are not easily separated (Corner et al. 2014). When decision-makers perceive that uncertainty needs to be reduced, they seek information they can quickly and easily obtain and interpret in order to decide whether a decision is needed and what it might entail at a particular moment in time (Morss et al. 2005). It is important to note that the highly politicized and partisan public discourse surrounding climate change (McCright and Dunlap 2011) can be amplified by trust and distrust relationships. Thus, a farmer statement of uncertainty may be a reflection of cultural and social factors associated with political identity, social relationships, resistance to change, financial contexts, and other obligations. Scientific uncertainty, through this lens, is less a cause of inaction than a justification for inaction, and one reaffirmed by social relationships and political cultural norms.

Hypotheses. This discussion on uncertainty suggests there are several factors that might explain why a large number of farmers in the Upper Midwest perceive there is too much uncertainty about the impacts of climate change to justify changing agricultural practices. Those factors conceptually involve (1) farmers' beliefs about climate change; (2) their experiences with extreme high profile weather events, such as flooding or drought; (3) perceptions of risk associated with concern about heat stress to crops or too much/too little water; and (4) public and private agriculture networks as sources of information. The four following hypotheses are proposed to assess the effect each has on what farmers claim as "too much uncertainty" in the impacts of climate change to merit making changes in current practices:

- H1: Beliefs about climate change. Uncertainty about whether climate change is occurring will be positively associated with greater uncertainty about the impacts of a changing climate justifying adjustments in current agricultural practices and strategies.

- H2: Experiences of flooding and drought. (1) Farmers who report having no experiences with drought over the past five years are more likely to perceive there is too much uncertainty about the impacts of climate change to justify changing current agricultural practices and strategies; (2) farmers who report having no experiences with flooding over the past five years are more likely to perceive there is too much uncertainty about the impacts of climate change to justify changing current agricultural practices and strategies.

- H3: Concern about excess water or heat stress on crops. (1) Farmers who report having lower levels of concern about water-related risks to their farm are more likely to perceive there is too much uncertainty about the impacts of climate change to justify changing current agricultural practices and strategies; (2) farmers who report having no concern about increased heat stress on their crops are more likely to perceive there is too much uncertainty about the impacts of climate change to justify changing current agricultural practices and strategies.

- H4. Public and private sector influence on uncertainty. (1) Farmers who report higher levels of influence of the agribusiness sector on their agricultural decisions are more likely to perceive there is too much uncertainty about the impacts of climate change to justify changing current agricultural practices and strategies; (2) farmers who report higher levels of influence of the public sector on their agricultural decisions are less likely to perceive there is too much uncertainty about the impacts of climate change to justify changing current agricultural practices and strategies.

\section{Materials and Methods}

Mixed Methods Design. This study utilizes an embedded design for conducting mixed methods analysis (Creswell and Clark 2011). An embedded design allows researchers to collect and analyze both quantitative and qualitative data within a traditional design and then utilize one element, in this case qualitative, to enhance and enrich the overall interpretation of the quantitative results. Integrating qualitative data through the inclusion of quotations elaborates the quantitative model interpretation, provides further transparency, and allows researchers to ground-truth results (Prokopy 2011). Quantitative data were gathered in early spring of 2012 using a stratified random sample survey of corn-soybean farmers from 11 states across the US Upper Midwest (Arbuckle et al. 2013c). Two sample frame criteria were used to select participants: operations with a minimum of US $\$ 100,000$ of gross sales in 2007 and at least 32.3 ha $(80 \mathrm{ac})$ of corn production. The sample was stratified by 22 contiguous watersheds and represented more than $60 \%$ of corn production in the United States. The mail survey was sent to 18,707 eligible farmers using a three-wave mailing process: first a survey was mailed, then a postcard reminder, and then a second survey was sent to nonresponders (Dillman et al. 2009). Completed surveys were received from 4,778 farmers with an effective response rate of $26 \%$. A nonresponse bias test was conducted at the watershed level and there were no meaningful differences detected between respondents and nonrespondents. This indicates that the survey sample is generally representative of the 
target population (see Arbuckle et al. [2013c] for survey methodology details).

Qualitative data were collected via semistructured in-person interviews with farmers across the Upper Midwest in 2013 (Roesch-McNally et al. in review). As part of a multistate research effort, the interview protocols were designed to explore adaptive and mitigative strategies that could be implemented to decrease their and other farmers' vulnerability to the impacts of climate change across the Upper Midwest United States. Interviews were conducted with 159 farmers across nine states: Illinois (9), South Dakota (14), Missouri (16), Ohio (18), Indiana (20), Iowa (20), Minnesota (20), Michigan (20), and Wisconsin (22). Interviews occurred after the historic 2012 drought that impacted much of the Upper Midwest and during an unusually wet 2013 growing season. In recent years, this region has experienced more extreme and variable weather, resulting in longer periods of drought and more intense rain events (Pryor et al. 2014). Participants were purposively recruited as part of the land grant extension and affiliated agricultural conservation networks in each state. Farmer participants were large-scale commodity producers (annual gross revenue of US $\$ 100,000$ or more) who primarily raise corn and soybean. This sample of farmers tended to be more conservation-oriented and were specifically recruited because the research team wanted to learn from individuals who had some exposure and experience with key conservation practices (e.g., no-till, cover crops, and precision agriculture). Further, these individuals are more likely to have surmounted barriers when adopting these practices.

Data analysis was conducted for both data sources concurrently. The quantitative model employs logistic regression in order to model relationships between 10 covariates and a binary measure of uncertainty in response to climate change impacts. The qualitative data analysis examined complementary in-depth interview quotations that support and expand on the findings from the logistic regression model. The objective of this approach is to utilize the in-depth interviews to complement and enrich the interpretation of the quantitative model by providing in-text quotations to assure transparency in the presentation of results (Prokopy 2011).

Variables in the Model. In the survey, farmers were asked their level of agreement with the following statement: "There's too much uncertainty about the impacts of climate change to justify changing my agricultural practices and strategies." Farmer responses to this question (figure 1) provided the foundation for the development of the dependent variable (Too Much Uncertainty). The original scale of the variable was measured on a five-point Likert scale where farmers rated their level of agreement from strongly disagree (1) to strongly agree (5). To construct a binary dependent variable, responses were condensed so that those farmers who agreed and strongly agreed that there was too much uncertainty to justify changing practices were coded as 1 ("too much uncertainty") and those farmers who disagreed or strongly disagreed were coded as a 0 .

Seven independent variables representing indicators of the four conceptual areas of influence and three control variables (Education, Farm Revenue, and All Cattle) were included in the model (table 1). The first independent variable representing climate change beliefs (CCBelief) was measured on an ordinal scale where $1=$ climate change is not occurring and $5=$ climate change is occurring and is mostly caused by human activity.

Two variables were used to measure experience with extreme weather hazards (Drought and Flood) and two variables were used to measure concern regarding weather related risks (Water Concern and Heat Concern). The Drought and Flood variables were binary measures assessing whether farmers had experienced drought or flooding on their farms over the past five years (2007 to 2012). The Water Concern variable was constructed using a summated scale constructed by summing responses on four survey items (table 1) that elicited a response on a four-point scale measuring concern about excess water as risks to their production ranging from not concerned (1) to very concerned (4), then dividing the sum by the number of items to facilitate comparability between scales. For the Water Concern scale, the Cronbach's alpha reliability coefficient (a measure of internal reliability for a scale of items [Field 2009]) value was 0.84. A binary measure for Heat Concern was used to measure farmers' concern about increased heat stress on crops, with $0=$ not concerned and $1=$ concerned.

Two variables measured the influence of agricultural social networks on farmers' level of uncertainty (Agribusiness and PublicAg). The Agribusiness variable was developed by constructing a summated scale based on responses to two survey items that elicited a response on a five-point Likert scale measuring influence of agribusiness (farm chemical dealers and seed dealers) on agricultural practices and strategies. The scale ranged from no contact (0) to strong influence (4), then the sum was divided by the number of items in the scale. The Cronbach's alpha reliability coefficient for Agribusiness was estimated as 0.83. The PublicAg variable was constructed by summing responses on five survey items (state department of agriculture, state climatologist, conservation nongovernmental organizations [NGOs], land grant university extension, and USDA Natural Resources Conservation Service [NRCS]) that elicited a response on a five-point Likert scale measuring influence of public sector agricultural advisors on agricultural practices and strategies. The scale ranged from no contact $(0)$ to strong influence (4), with the sum divided by the number of items. The Cronbach's alpha reliability coefficient was estimated as 0.85 .

Data Analysis. For the quantitative data analysis, a binary logistic multivariate regression model was then constructed to analyze farmers' uncertainty about changing their behavior in response to climate change. Binary logistic regression is an appropriate statistical model to use when assessing a dependent variable that is dichotomous (Hair et al. 2010). In this analysis we examined those who reported that they were certain (0) and those who claimed "too much" uncertainty (1), dropping the neutral category, which reduced our effective sample size for analysis to 3,267.

Interviews were digitally recorded, transcribed verbatim, and analyzed with NVivo 10 qualitative analysis software (QSR International Pty Ltd., Melbourne, Australia). The analysis went through many iterative stages of coding by multiple researchers on the project team. The coding procedure followed an open, axial and selective coding procedure (Charmaz 2006), whereby we sought to examine multiple factors that were relevant to the interview protocol, which took place over multiple time frames in order to examine the quality and reliability of the qualitative data across all of the interviews. For this analysis, data were explicitly coded so that they were complimentary to the quantitative data, which is common in other mixed 
Table 1

Descriptive statistics for variables used in analysis $(n=3,267)$.

\begin{tabular}{|c|c|c|c|c|}
\hline Variable & Question & Measure & Mean & SD \\
\hline \multicolumn{5}{|l|}{ Dependent variable } \\
\hline Too Much Uncertainty & $\begin{array}{l}\text { There's too much uncertainty about the impacts } \\
\text { of climate change to justify changing my } \\
\text { agricultural practices and strategies. }\end{array}$ & $\begin{array}{l}\text { Binary response ( } 0 \text { = strongly disagree, } \\
\text { disagree, } 1 \text { = strongly agree, agree) }\end{array}$ & 0.895 & 0.307 \\
\hline \multicolumn{5}{|l|}{ Independent variables } \\
\hline CCBelief & What is your belief about climate change? & $\begin{array}{l}\text { Ordinal ( } 1 \text { = climate change not } \\
\text { occurring; } 2 \text { = not sufficient evidence } \\
\text { to know with certainty whether climate } \\
\text { change is occurring; } 3 \text { = climate change } \\
\text { is occurring, caused mostly by natural } \\
\text { changes; } 4 \text { = climate change is occurring, } \\
\text { caused equally by natural and human } \\
\text { activities; } 5 \text { = climate change mostly } \\
\text { caused by human activities) }\end{array}$ & 3.25 & 1.028 \\
\hline Flood & Experienced flooding over the past five years. & Binary response $(0=$ no; $1=$ yes $)$ & 0.358 & 0.480 \\
\hline Water Concern & $\begin{array}{l}\text { Summated scale measuring concern about } \\
\text { water related risks (flooding + extreme } \\
\text { rains }+ \text { increased saturation }+ \text { increased } \\
\text { erosion/4). }\end{array}$ & $\begin{array}{l}\text { Four point scale }(1 \text { = not concerned; } \\
2 \text { = slightly concerned; } \\
3 \text { = concerned; } \\
4 \text { = very concerned) }\end{array}$ & 2.262 & 0.696 \\
\hline Heat Concern & Concern about increased heat stress on crops. & $\begin{array}{l}\text { Binary response }(0=\text { not concerned, } \\
\text { slightly concerned; } 1 \text { = concerned, } \\
\text { very concerned) }\end{array}$ & 0.561 & 0.491 \\
\hline Agribusiness & $\begin{array}{l}\text { Summated scale measuring influence of } \\
\text { agribusiness on agricultural practices and } \\
\text { strategies (farm chemical dealer }+ \text { seed } \\
\text { dealer/2). }\end{array}$ & $\begin{array}{l}\text { Five point scale }(0=\text { no contact; } 1=\text { no } \\
\text { influence; } 2 \text { = slight influence; } \\
3 \text { = moderate influence; } \\
4 \text { = strong influence) }\end{array}$ & 2.763 & 0.767 \\
\hline Education & Highest level of education. & $\begin{array}{l}\text { Ordinal scale ( } 1 \text { = some formal } \\
\text { education; } 6 \text { = graduate school) }\end{array}$ & 3.364 & 1.351 \\
\hline Farm Revenue (US\$) & Farm revenue.* & Continuous & 478,975 & 904,437 \\
\hline All Cattle & Count for all cattle and calves. * & Continuous & 78 & 327 \\
\hline
\end{tabular}

method embedded designs (Creswell and Clark 2011). The four categories that were coded for the qualitative analysis included the following: beliefs about climate change, concerns about extreme weather events, experiences with extreme weather events, and trusted information sources.

\section{Results and Discussion}

The Upper Midwest region climatological gradient of wet and dry areas with substantial scientific uncertainty as to specific locations that will experience wetness and drought seasonally and across years (Morton et al. 2015; Arritt 2016) is the context in which qualitative and quantitative data are examined. Farmers' concern about the unpredictability of weather can translate into uncertainty that they attempt to account for and manage. These comments by project farmers reflect common observations about the weather:

Well, my real concern about climate change is...the wind patterns and what that affects, rainfall, either getting too much [water], too little [water]...the Midwest... [is] the bread basket of the United States. [It] is that way because we 
have predictable rainfall and my concern is unpredictability. It doesn't lend itself well to producing a crop or planting for anything. (Wisconsin farmer)

...this year it's way too wet. Last year it was plenty dry. The year before that it was cold and wet initially and then it got too dry after that. I guess you just need to be flexible. You need to do the best you can so that you're not locked into a corner. (Michigan farmer)

Results from the random sample survey show the majority $(89.5 \%)$ of farmers in the Upper Midwest (figure 1 and table 1) perceived there was too much uncertainty about the impacts of climate to justify changing their agricultural practices and strategies. Beliefs about climate change causality ranged from claims that climate change is not occurring $(3.5 \%)$, to there is not sufficient evidence to know with certainty whether climate change is occurring or not (30.9\%), to acknowledgements that climate change is occurring but caused mostly by natural changes in the environment $(24.6 \%)$, to beliefs it is occurring but caused more or less equally by natural changes in the environment and human activities (33.1\%), to occurring but caused mostly by human activities (7.8\%).

Thirty-two percent of farmers reported experiencing drought and 36\% reported experiencing flooding over the past five years (table 1). On average, farmers were slightly concerned (2.26) about risks of excess water and $56.1 \%$ were concerned or very concerned about increased heat stress on crops. Farmers reported that farm chemical dealers and seed dealers representing agribusiness had a moderate influence (2.76) on their agricultural practices and strategies, and public agricultural agencies had a much lower influence, somewhere between no influence and slight influence (1.61). On average, farmers had graduated from high school and had some college education, owned 78 head of cattle and calves, and reported annual farm revenue of US $\$ 478,975$.

Model fit statistics for the binary logistic regression model were found to be adequate (Hosmer and Lemeshow test statistic 10.84 [ $p$ $=0.21]$ ) (table 2). Nagelkirke's Psuedo- $R^{2}$ of 0.08 indicated that the independent variables only explained a small portion of the variance in the dependent variable. However, results suggest some clear relationships between the independent variables and farmer per-

\section{Table 2}

Factors that influence Upper Midwest corn-soybean farmers' perceptions that "there is too much uncertainty about the impacts of climate change to justify changing my agricultural practices and strategies" (binary logistic regression).

\begin{tabular}{lcccc}
\hline Variable & $\begin{array}{l}\text { Logit } \\
\text { coefficient }\end{array}$ & se & p-value & $\begin{array}{c}\text { Exp(B) } \\
\text { odds ratio }\end{array}$ \\
\hline Intercept & 3.212 & 1.231 & 0.009 & 24.837 \\
CCBelief & -0.485 & 0.066 & $<0.0001$ & 0.615 \\
Drought & -0.263 & 0.138 & 0.056 & 0.768 \\
Flood & 0.095 & 0.142 & 0.506 & 1.099 \\
Water Concern & -0.108 & 0.109 & 0.322 & 0.898 \\
Heat Concern & -0.451 & 0.146 & 0.002 & 0.637 \\
Agribusiness & 0.212 & 0.089 & 0.017 & 1.236 \\
PublicAg & -0.188 & 0.084 & 0.025 & 0.829 \\
Education & -0.050 & 0.048 & 0.290 & 0.951 \\
Farm Revenue & 0.082 & 0.091 & 0.371 & 1.085 \\
All Cattle & -0.027 & 0.029 & 0.350 & 0.973 \\
\hline
\end{tabular}

Notes: Hosmer and Lemeshow ( $p$-value) 10.84 (0.21). Nagelkirke's Psuedo- $R^{2}=0.08$.

ceptions of too much uncertainty about climate change impacts to justify changing practices and strategies. Four indicators were significant $(p<0.05)$ predictors of too much uncertainty: beliefs about climate change, heat stress concern, and both agricultural network influence scales. A fifth indicator, experience with drought, was significant at $p=0.056$, slightly above the $p<0.05$ cutoff. These findings are presented below and illustrated using farmer interviews.

Beliefs about climate change were negative and significantly $(-0.485, p<0.0001)$ associated with perceptions of too much uncertainty regarding the impacts of climate change to justify adjusting their practices (table 2). Uncertainty in the evidence about climate change or causality beliefs that it is a natural cycle were reflected in claims of too much uncertainty about climate change impacts. The qualitative data offer a deeper view of farmers' uncertainty as they assess changes in climate conditions and potential causes. Project farmers from three Upper Midwest states reveal some of their thinking:

...there's really not enough data yet to support either way...the world's still changing...It's kind of hard to put a number on what the human impact is on it compared to what would naturally be happening anyway, with the continental shifts and everything else. (Wisconsin farmer)

So that's only like 140 years' worth of data which is a geological blink of an eye...this extreme weather, hot, dry, maybe it was always like this and the last
150 years was just when we all settled it and took all this data... We don't have near enough data to, I feel, to jump to conclusions. (Iowa farmer)

Now, I'm not sure how much things are actually changing. When they talk about the world temperature change, 2/10 of a degree in a year [relative to past history]. I don't know. I wish I had a dinosaur around to ask him... what kind of changes I should be looking at. I'm just not too tore up about the weather and changes right now. (Indiana farmer)

Both quantitative and qualitative data support the first hypothesis, that uncertainty about the evidence for climate change and beliefs about climate change being a natural cycle will be associated with perceptions that there is too much uncertainty about the impacts of a changing climate to justifying making changes in current agricultural practices and strategies. This can be interpreted as farmers who are not convinced there is sufficient evidence that climate change is occurring, and that humans are not the cause, are also likely to claim there is too much uncertainty to justify doing anything differently in their current production system. Conversely, farmers who believe climate change is occurring and caused mostly by human activities are more likely to have lower levels of uncertainty about climate impacts and may be more willing to adjust their practices because of projected future climate change impacts. 
Experiences with Excess Water or Drought. It was hypothesized that experiences with significant flooding of farmland over the last five years would reduce a farmer's sense of uncertainty. Similarly, it was hypothesized that significant experience with drought on land that was farmed over the last five years would reduce farmers' sense of uncertainty about climate change impacts. Although flooding experience was not significantly different between the uncertain and certain farmers, experience with drought was significant at the $p=0.056$ level. This suggests that experience with drought decreased the sense of uncertainty about climate change impacts and that adjustments might be needed in response to that experience. Farmer interviewees reflected on the heavy rains and droughts they have been experiencing and revealed efforts they are making to understand the variability in weather.

It seems that our rains are less frequent, they're heavier, they're more intense than they were, that I ever remember...not to say we didn't have wet falls back then [when I first started to farm] I remember very wet falls. I remember wet springs. I remember dry springs, dry falls. But it just seems like, when we get rain now, it's a couple inches at a time or it's just a trace. (Wisconsin farmer)

We've seen both ends of the spectrum. We've had extreme floods, one of the wettest years on record. Last year in 2012 we experienced drought, driest year... top three, I think, on record. This year, the months of March, April, and May were the wettest three on record in the last 141 years...back and forth, from one extreme to the other and we have not landed in the middle. (Iowa farmer)

Concern about Excess Water and Heat Stress. Two variables, excess water risks and heat stress on crops, represented concern that these events could negatively influence farmers' production systems. Concern about water-related risks such as flooding, extreme rains, increased saturated soil, or increased erosion were not significantly associated with too much uncertainty about climate impacts to justify changing current practices. However, concern about increased heat stress on crops was negative and significant $(-0.451, p=0.002)$ (table 2). This is inter- preted as farmers who were not concerned about heat stress were likely to perceive there is too much uncertainty about the impacts of climate change to justify making any adjustments to their current practices. Conversely, those farmers who were concerned about heat stress were likely to have much lower levels of uncertainty about whether climate impacts justify making changes in their production system. Farmer interviews also revealed concern about extreme heat, as the following remark illustrates:

I'm concerned about it very much... If we start getting into those really hot temperatures...I don't know if we will or not, but really hot temperatures in the summertime, that's going to change the way we have to farm...can you imagine if it got so dry here that you'd have to go back to all grassland for cattle...the notill may be...a way to defer that, prevent it...slow it down. (South Dakota farmer)

Agricultural Networks Influence on Too Much Uncertainty. PublicAg $(-0.188, p=$ $0.025)$ and Agribusiness $(0.212, p=0.017)$ influences on agricultural practices were significantly associated with levels of uncertainty that changes should be made to current practices because of climate change impacts, but in differing directions. Farmers who reported being strongly influenced by agribusiness (i.e., farm chemical and seed dealers) were more likely to perceive that there is too much uncertainty about climate impacts to justify changing current agricultural practices or strategies. This suggests that agribusiness as a trusted information source is reaffirming that climate impacts are uncertain and now is not the time to be making changes in current practices. Farmers who reported being strongly influenced by public sector agricultural relationships (i.e., state climatologists, Extension, state departments of agriculture, conservation NGOs, and NRCS) were more likely to have lower levels of uncertainty about whether climate impacts merited making changes in their system. This suggests that farmers using public agencies and organizations as information sources may be decreasing their uncertainty about climate impacts, which could result in greater willingness to adapt or adjust practices. Farmer interviews indicated that they interact extensively with public agricultural organizations and agribusiness. Many of these networks were sources of information that farmers' reported to be helpful and useful.

I went to an Extension meeting...they had a demonstration of different vertical tillage and deep tillage type combinations... and that helped me in my decision...I've talked to different people. (Michigan farmer)

[I] went to different seminars, drought, whether it's through Farm Bureau or Corn Growers, ... seed companies...everybody has a weather guy... [I also read] magazine or internet...different articles about climate change. (Missouri farmer)

Controls. Farmer education, farm revenue, and whether the operation was a crop or cattle production system control variables were not significantly associated with a sense of too much uncertainty about climate impacts.

Implications. Farmers, like all individuals, only have a partial understanding of the world where they live, and it is in the context of these always-incomplete understandings that they make judgements and decisions (Simon 1983; Sarewitz 2004). The data, both quantitative and qualitative, reveal Upper Midwest farmers' judgements of uncertainty are significantly associated with their climate change beliefs, concern about heat stress on crops, and agricultural networks. The significance and negative directionality of climate change beliefs are evidence that uncertainty levels are increased when causality beliefs are not attributed to human causes. This suggests that beliefs are reinforcing a sense of uncertainty, which may signal that farmers do not believe they can control the weather's impacts by additional adjustments or changes in their management. Actual experiences with drought and flooding as well as water risk concerns did not seem to significantly influence their uncertainty assessment. This suggests that farmers' actual experiences with extreme weather events may not be key drivers of their uncertainty. However, higher levels of heat concern reduced levels of uncertainty, revealing that perceptions of increased temperature risks might lead to adjustments in practices to reduce climate risks. Agribusiness and public agriculture are both significant information sources, but generate opposite responses to uncertainty. Greater levels of influence by agribusiness seem to increase judgements of uncertainty, 
and higher levels of influence by public agriculture seem to reduce uncertainty. These trusted information sources could be amplifying and reaffirming or discrediting climate messages in ways that reflect farmer beliefs and cultural norms.

Findings suggest a combination of lack of locally relevant information that is easily accessible for farmers and social reinforcement of climate beliefs influence farmer uncertainty. The high level of uncertainty about climate change among Midwestern farmers could indicate that they, like other decision-makers, may not have sufficient tools for unpacking climate science predictions and in some cases may not have access to locally relevant and reliable climate and management information in the first place. Decision-makers tend to react to short-run feedbacks and immediate crises rather than trying to forecast the future, which is considered much too uncertain to act on (Slovic 2009). As a result, they are likely to employ a variety of mechanisms to reduce uncertainty or avoid dealing with the complexity of climate change entirely (Slovic 2009).

The implications of misjudging uncertainties associated with climate and nonclimate situations have been found to not only influence whether adaptation occurs, but also the type and timing of adaptation and degree of effort made (Kettle and Dow 2016). Adger et al. (2009) propose that one of the barriers to addressing uncertainty is that "...science has claimed a greater degree of predictability for the climate system than it has offered for other, adaptation-relevant, dimensions of social change relating to economics, technology, demography and culture.'They conclude that how these knowledge claims about future climate are assimilated into adaptation decision-making will greatly affect whether climate uncertainty is reduced. Farmers must first have some level of certainty that climate change is happening and will have consequences to their farm enterprise to consider changing their farm management. They must also have a degree of certainty that they have some control and a belief that they can affect the situation by their adaptation responses.

Farmers grow their crops in particular locales and make management decisions based on specific weather conditions they have experienced in the past using the advice of trusted crop advisors. Average weather and climate patterns for the United States or even the Midwest region are not particularly useful when farmers make field specific decisions that affect germination, seedling growth, rooting depth, pollination, grain fill, and harvest. Howden et al. (2007) claim that, "farmers may find limited utility in long-term projections of climate, given the high uncertainties at the finer spatial and temporal scales at which their decisions are made." However, farmers already factor in some level of uncertainty into routine management decisions.

The probabilistic framework in which climate science and impacts are presented may be interpreted as having high levels of uncertainty - or lack of scientific consensus around a scientific principle-than scientists intend, potentially leading to adaptation avoidance. Improvements in farmers' probability estimates of climate change hazards and risks as well as understanding projected impacts on their cropping system(s) may lead to greater willingness to adapt. In cases where uncertainty is caused by insufficient information, it can be reduced with the use of historical and longitudinal crop and weather records, graphs of recurrent events, photographs, and maps that keep accurate data in front of the farmer in ways that provide accurate feedback about the past and improve their estimates of future risk and the outcomes they might expect under different conditions and practices (Morton 2008; Slovic 2009; McGuire et al. 2013; Wilke and Morton 2016). Decision support tools and simulations can give farmers a realistic experience in making decisions under uncertainty and offer opportunities to experiment with different practices and climate scenarios so they are better prepared for the future (Slovic 2009; Prokopy et al. 2013; Haigh et al. 2015). However, more information may be insufficient to address claims of uncertainty when differing political and cultural norms contest the parameters of climate change.

\section{Summary and Conclusions}

Climate change has been labeled a "wicked" social problem (Grundmann 2016). Those that are convinced that building the case for scientific consensus is good climate policy often claim the lack of progress toward proactive response lies in misinformation, insufficient information, or limited capacity to properly translate science (Grundmann 2016; Sarewitz 2004). However, it is not simply a matter of more science education or of modifying beliefs and values. The source of this uncertainty is complex and nuanced as farmers' uncertainty is driven by their experiences of actual weather events, perception of climate risks, and linkages with their understanding of climate science information. Additionally, uncertainty in climate science information is tied to personal values and beliefs and broader social norms that may deepen distrust of climate science information. More and better scientific information and accessible translation are not likely to be enough to combat this uncertainty given the linkages with values, beliefs, and social norms, particularly those linked to political party as climate change continues to be a source of partisan divide in the United States (McCright and Dunlap 2011).

This complexity is reflected by the small proportion of variance the model in this paper explains. There is much more to be understood about the relationships among climate science, weather risk concerns, values and beliefs, and social influences on farmer uncertainty related to changes in practices. Is the low explanatory power due to the specific variables selected to represent concepts of climate science, experience, and social influence; or are there major conceptual areas missing in the model? On the other hand, is there a need for a different methodological approach to better represent the complexity of decision-making? Data on farmer responses to media reports on climate change and political affiliation variables were not available for this analysis, so it is not known whether partisan climate beliefs or media approaches are influencing uncertainty. Much more research is needed to disentangle the connection between climate science, values, and claims of uncertainty.

Revisiting four reasons why farmers may claim uncertainty as a justification for inaction as explored in this paper provide insight into where future research might be fruitful. The first, human (mis)judgement of risk, suggests a need for deeper understanding of how Upper Midwest corn-soybean farmers may misjudge the risks associated with a changing climate-especially relevant given the record crop and per acre yield increases in recent years. The second reason, scientific uncertainty, may extend beyond meanings assigned to climate causality and global climate patterns to more practical uncertainty associated with the inaccuracies of local weather projections as they affect crop management decisions and uncertainty in the farm operation. Three, political and social 
discourse associated with anthropogenic climate change may influence claims of uncertainty due in large part to the partisan debate about the causes of climate change, particularly in the United States. Fourth, farmers may not yet have framed climate change as a problem they need to respond to, particularly in relation to other economic (e.g., declining commodity prices) and environmental (e.g., water quality concerns with production) concerns, and thus no action is yet justified. One of the key insights from this paper is the recognition that all of these positions are potentially valid. Midwest corn-soybean farmers are not homogenous in their experiences, values and beliefs, and perceptions of risk (Arbuckle et al. 2014). Future research designs should incorporate the complexity of decision making, including localized social dynamics of historically and generationally referenced experiences and behaviors that influence perceptions of current and projected future climate conditions (Wilke and Morton 2016).

Uncertainty is inherent in most scientific findings with the new knowledge created rarely providing answers or predictions with absolute certainty (Dessai and Hulme 2007; Rabinovich and Morton 2012). The growing body of knowledge about climate and other global changes including climate projections, impacts and vulnerability assessments, and different adaptation strategies suggests that the agricultural sector is coping with a wide range of technically complex scientific concepts (Melillo et al. 2014; Lourenco et al. 2015). Even as we learn more, there will never be "perfect" information to reduce all uncertainties associated with climate change, and information is filtered through personal beliefs and values. The growing and sometimes controversial body of knowledge and associated uncertainties need to be communicated in relevant ways to farmers and their trusted information sources (Wilke and Morton 2015a, 2015b; Lourenco et al. 2015). The way climate science uncertainty is communicated is critical to how it is interpreted by farmers and whether they respond (Wilke and Morton 2015a).

Scientists often produce information for decision-makers without accounting for the origin of the uncertainty (Morss et al. 2005). Rabinovich and Morton (2012) stress the importance of understanding the diversity of beliefs held by publics in order to manage how uncertainty in climate science is understood. Further, where uncertainty is incompatible with beliefs and expectations that scientific research will deliver absolute certainty, scientists and Extension educators need to consider their role in reshaping those beliefs. Scientific models are malleable and efforts to engage farmers in a broader conversation about the process of developing sound climate science may better prepare farmers to accept greater levels of uncertainty while still preparing for and adapting to a changing climate.

Our work suggests that Midwest cornsoybean farmers are conveying the message, "I need a lot more certainty about the impacts of climate change on my farm before I am ready to make changes in my practices.' This work raises important questions about how to resolve uncertainty by asking, how much certainty is required in climate change projections to justify investment in adaptation (Dessai and Hulme 2007)? Can this level of certainty be delivered? And if claims of uncertainty are amplified by the contested nature of climate change, how can we socially ratchet down the polarization? These questions should be grappled with further in future efforts to examine uncertainty among farmers and natural resource managers in the era of climate change.

\section{Acknowledgements}

This research is funded by the regional collaborative project supported by the USDA National Institute of Food and Agriculture (NIFA), Award No. 2011-68002-30190, Cropping Systems Coordinated Agricultural Project: Climate Change, Mitigation, and Adaptation in Corn-based Cropping Systems.

\section{References}

Adger, W.N., J. Barnett, K. Brown, N. Marshall, and K. O'Brien. 2013. Cultural dimensions of climate change impacts and adaptation. Nature Climate Change 3:112-118.

Adger, W.N., S. Dessai, M. Goulden, M. Hulme, I. Lorenzoni, D.R. Nelson, L.O. Naesss, J. Wolf, and A. Wreford. 2009. Are there limits to adaptation to climate change? Climatic Change 93:335-354, doi:10.1007/ s10584-008-9520-z

Arbuckle Jr., J.G., J. Hobbs, A. Loy, L.W. Morton, L. Prokopy, and J. Tyndall. 2014. Understanding farmer perspectives on climate change: Toward effective communication strategies for adaptation and mitigation in the Corn Belt. Journal of Soil and Water Conservation 69(6):505-516, doi:10.2489/jswc.69.6.505.

Arbuckle Jr., J.G., L.W. Morton, and J. Hobbs. 2013a. Farmer beliefs and concerns about climate change and attitudes toward adaptation and mitigation: Evidence from Iowa Climatic Change 118:551-563.

Arbuckle Jr., J.G., L.W. Morton, and J. Hobbs. 2013b. Understanding farmer perspectives on climate change adaptation and mitigation: The roles of trust in sources of climate information, climate change beliefs and perceived risk. Environment and Behavior: 0013916513503832

Arbuckle Jr., J.G., L.W. Morton, and J. Hobbs. 2015. Trust, beliefs, and perceived risk as determinants of farmer support for adaptive and mitigative responses to climate change. Environment and Behavior 47(2):205-234, doi: 10.1177/0013916513503832.

Arbuckle Jr., J.G., L.S. Prokopy, T. Haigh, J. Hobbs, T. Knoot, C. Knutson, A. Loy, A.S. Mase, J. McGuire, L.W. Morton, J. Tyndall, and M. Widhalm. 2013c. Climate change beliefs, concerns, and attitudes toward adaptation and mitigation among farmers in the Midwestern United States. Climatic Change 117:943-950, doi:10.1007/ s10584-013-0707-6

Arritt, R. 2016. Climate change in the Corn Belt CSCAP-0193-2016. Ames, IA: Cropping Systems Coordinated Agricultural Project (CAP): Climate Change, Mitigation, and Adaptation in Corn-based Cropping Systems.

Batie, S. 2008. Wicked problems and applied economics. American Journal of Agricultural Economics 5:1176-1191.

Carolan, M.S. 2006. Social change and the adoption and adaptation of knowledge claims: Whose truth do you trust in regard to sustainable agriculture? Agriculture and Human Values 23:325-39.

Charmaz, K. 2006. Constructing Grounded Theory. Los Angeles, CA: Sage Publications.

Corner, A., E. Markowitz, and N. Pidgeon. 2014. Public engagement with climate change: The role of human values. WIREs Climate Change 5:411-422, doi:10.1002/wcc.269.

Crane, T.A., C. Roncoli, and G. Hoogenboom. 2011. Adaptation to climate change and climate variability: The importance of understanding agriculture as performance. NJAS-Wageningen Journal of Life Sciences 57:179-185, doi:10.1016/j.njas.2010.11.002.

Creswell, J.W., and V.L. Plano Clark. 2011. Designing and Conducting Mixed Methods Research.Thousand Oaks, CA: Sage Publications.

Dahlstrom, M.F. 2014. Using narratives and storytelling to communicate science with nonexpert audiences. Proceedings of the National Academy of Sciences of the United States of America,Vol. 111, Supplement 4, 13614-20.

Dessai, S., and M. Hulme. 2007. Assessing the robustness of adaptation decisions to climate change uncertainties: A case study on water resources management in the East of England. Global Environmental Change 17(1):59-72. Dietz, T., A. Dan, and R. Shwom. 2007. Support for climate change policy: Social psychological and social structural influences. Rural Sociology 72:185-214. 
Dillman, D., J. Smyth, and L. Christian. 2009. Internet, Mail and Mixed-Mode Surveys:The Tailored Design Method. Hoboken, NJ: John Wiley \& Sons.

Frewer, L.J., S. Hunt, M. Brennan, S. Kuznesof, M. Ness, and C. Ritson. 2003. The views of scientific experts on how the public conceptualize uncertainty. Journal of Risk Research 6(1):75-85.

Funtowicz, S.O., and J.R. Ravetz. 1993. Science for the postnormal age. Futures 25:739-755.

Gleick, P. 2012. Climate change, disbelief, and the collision between human and geologic time. Forbes. http:// www.forbes.com/sites/petergleick/2012/01/16/ climate-change-disbelief-and-the-collision-betweenhuman-and-geologic-time/.

Grundmann, R. 2016. Climate change as a wicked social problem. Nature Geoscience 9:562-563.

Haigh, T., E. Takle, J.Andresen, M. Widhalm, J.S. Carlton, and J.Angel. 2015. Mapping the decision points and climate information use of agricultural producers across the US Corn Belt. Climate Risk Management 7:2030.

Hair Jr., J.F., W.C. Black, B.J. Babin, and R.E. Anderson. 2010 Multivariate Data Analysis. Upper Saddle River, NJ: Prentice Hall.

Hatfield, J.L., K.J. Boote, B.A. Kimball, L.H. Ziska, R.C. Izaurralde, D. Ort, A.M. Thomson, and D. Wolfe. 2011. Climate impacts on agriculture: Implications for crop production. Agronomy Journal 103(2):351-370.

Howden, S.M., F. Soussana, F.N. Tubiello, N. Chhetri, M. Dunlop, and H. Meinke. 2007. Adapting agriculture to climate change. The National Academy of Sciences of the USA 104(50):19691-96.

Ingham, A., J. Ma, and A. Ulph. 2007. Climate change, mitigation and adaptation with uncertainty and learning. Energy Policy 35:5354-5369.

Kahan, D.M., H. Jenkins-Smith, and D. Braman. 2011. Cultural cognition of scientific consensus. Journal of Risk Research 14(2):147-174.

Kettle, N.P., and K. Dow. 2016. The role of perceived risk, uncertainty, and trust on coastal climate change adaptation planning. Environment and Behavior 48(4):579-606.

Kuhn, T.S. 1962. The Structure of Scientific Revolutions. Chicago, IL: University of Chicago Press.

Laurian, L. 2009. Trust in planning: Theoretical and practical considerations for participatory and deliberative planning. Planning Theory and Practice 10:369-391.

Lourenco, T.C., A. Rovisco, S. Dessai, R. Moss, and A. Petersen. 2015. Editorial introduction to the special issue on uncertainty and climate change adaptation. Climatic Change 132:369-372, doi:10.1007/s10584-015-1444-9.

Loy, A., J. Hobbs, J.G.Arbuckle Jr., L. W. Morton, L.S. Prokopy, T. Haigh, T. Knoot, C. Knutson, A.S. Mase, J. McGuire, J. Tyndall, and M. Widhalm. 2013. Farmer perspectives on agriculture and weather variability in the Corn Belt: A statistical atlas. CSCAP (Cropping Systems Coordinated Agricultural Project): Climate Change, Mitigation, and Adaptation in Corn-based Cropping Systems Coordinated Agricultural Project 0153-2013. Ames, IA.
McCright, A.M., and R.E. Dunlap. 2011. Cool dudes: The denial of climate change among conservative white males in the United States. Global Environmental Change 21:1163-1172.

McGuire, J., L.W. Morton, and A. Cast. 2013. Reconstructing the good farmer identity: Shifts in farmer identities and farm management practices to improve water quality. Agriculture and Human Values 30(1):57-69, doi: 10.1007/s10460-012-9381-y.

Melillo, J.M., T.C. Richmond, and G.W. Yohe. 2012. Highlights of Climate Change Impacts in the United States: The Third National Climate Assessment. Washington, DC: US Global Change Research Program.

Morss, R.E., O.V. Wilhelmi, M.W. Downton, and E. Gruntfest. 2005. Flood risk, uncertainty, and scientific information for decision making: Lessons from an Interdisciplinary Project. Bulletin of American Meteorological Society (BAMS) November 1593-1601, doi:10.1175/BAMS-86-11-1593.

Morton, L.W. 2008. The role of civic structure in achieving performance-based watershed management. Society and Natural Resources 21(9):751-766.

Morton, L.W., J. Hobbs, J.Arbuckle, and A. Loy. 2015. Upper Midwest climate variations: Farmer responses to excess water risks. Journal of Environmental Quality 44:810822, doi:10.2134/jeq2014.08.0352.

Nowak, P. 1992. Why farmers adopt production technology. Journal of Soil and Water Conservation 47(1):14-16.

Pielke Jr., R.A. 2007. The Honest Broker: Making Sense of Science in Policy and Politics. UK: Cambridge University Press.

Prokopy, L.S. 2011. Agricultural human dimensions research: The role of qualitative research methods. Journal of Soil and Water Conservation 66(1):9A-12A.

Prokopy, L.S., T. Haigh, A.S. Mase, J. Angel, C. Hart, C. Knutson, M.C. Lemos, Y.-J Lo, J. McGuire, and L.W Morton. 2013. Agricultural advisors: A receptive audience for weather and climate information? Weather, Climate, and Society 5(2).

Prokopy, L., L.W. Morton, J.G. Arbuckle, A. Wilke, and A. Mase. 2015. Agricultural stakeholder views on climate change: Implications for conducting research and outreach. Bulletin of Atmospheric Meteorological Society, doi 10.1175/BAMS-D-13-00172.1.

Pryor, S.C., D. Scavia, C. Downer, M. Gaden, L. Iverson, R. Nordstrom, J. Patz, and G.P. Robertson. 2014. Chapter 18: Midwest. In Climate Change Impacts in the United States: The Third National Climate Assessment, eds. J.M. Melillo, T.C. Richmond, and G.W. Yohe, 418-440. Washington, DC: US Global Change Research Program.

Rabinovich, A., and T.A. Morton. 2012. Unquestioned answers or unanswered questions: Beliefs about science guide responses to uncertainty in climate change risk communication. Risk Analysis 32(6):992-1002.

Roesch-McNally, G.E., J.G. Arbuckle, and J.C. Tyndall. In review. Soil as Socio-Ecological Feedback: Bridging short-term reactivity and long-term strategies for climate resiliency. Rural Sociology.

Sarewitz, D. 2004. How science makes environmental controversies worse. Environmental Science and Policy 7:385-403.

Simon, H.A. 1959. Theories of decision making in economics and behavioral sciences. American Economic Review 49:253-283.

Simon, H.A. 1983. Reason in Human Affairs. Stanford, CA: Stanford University Press.

Slovic, P. 2009. The Perception of Risk. Sterling,VA: Earthscan. Walsh, J., D. Wuebbles, K. Hayhoe, J. Kossin, K. Kunkel, G. Stephens, P. Thorne, R. Vose, M. Wehner, J. Willis, D. Anderson, S. Doney, R. Feely, P. Hennon, V. Kharin, T. Knutson, F. Landerer, T. Lenton, J. Kennedy, and R. Somerville. 2014: Chapter 2: Our Changing Climate. In Climate Change Impacts in the United States: The Third National Climate Assessment, eds. J.M. Melillo, T.C. Richmond, and G.W. Yohe. US Global Change Research Program, 19-67, doi:10.7930/ J0KW5CXT. http://nca2014.globalchange.gov/report/ our-changing-climate/introduction.

Walthall, C.L., J. Hatfield, P. Backlund, L. Lengnick, E. Marshall, M.Walsh, S. Adkins, M.Aillery, E.A.Ainsworth, C. Ammann, C.J. Anderson, I. Bartomeus, L.H. Baumgard, F. Booker, B. Bradley, D.M. Blumenthal, J. Bunce, K. Burkey, S.M. Dabney, J.A. Delgado, J. Dukes, A. Funk, K. Garrett, M. Glenn, D.A. Grantz, D. Goodrich, S. Hu, R.C. Izaurralde, R.A.C. Jones, S-H. Kim, A.D.B. Leaky, K. Lewers, T.L. Mader, A. McClung, J. Morgan, D.J. Muth, M. Nearing, D.M. Oosterhuis, D. Ort, C. Parmesan, W.T. Pettigrew, W. Polley, R. Rader, C. Rice, M. Rivington, E. Rosskopf, W.A. Salas, L.E. Sollenberger, R. Srygley, C. Stöckle, E.S. Takle, D. Timlin, J.W. White, R.Winfree, L.W. Morton, and L.H. Ziska. 2012. Climate Change and Agriculture in the United States: Effects and Adaptation. USDA Technical Bulletin No. 1935. Washington, DC: USDA.

Weber, E.U., and P.C. Stern. 2011. Public understanding of climate change in the United States. American Psychologist 66:315-328.

Wilke, A.K., and L.W. Morton. 2015a. Climatologists' communication of climate science to the agricultural sector. Science Communication p. 1-25, doi:10.1177/1075547015581927.

Wilke, A.K., and L.W. Morton. 2015b. Climatologists' patterns of conveying climate science to the agricultural community. Agriculture and Human Values 32(1):99110, doi:10.1007/s10460-014-9531-5.

Wilke,A.K., and L.W.Morton. 2016.Analog years: Connecting climate science and agricultural tradition to better manage landscapes of the future. Climate Risk Management. http://dx.doi.org/10.1016/j.crm.2016.10.001. 